\title{
ENGINE COOLING SYSTEM WITHOUT RADIATOR
}

\author{
İsmail Durgun, Arda Odabaşığlu, Hasan Ayartürk \\ TOFAŞ-FIAT R\&D Center Bursa / Turkey \\ E-mails: ismail.durgun@tofas.com.tr, arda.odabasioglu@tofas.com.tr, \\ hasan.ayarturk@tofas.com.tr
}

\begin{abstract}
The vehicle engine cooling system, ethylene glycol (antifreeze) added cooling water circulation pump, radiator and radiator fan with components that control components consist of linking the plumbing and electrical installation.

This study have been made presentation an engine cooling system radiator has been cancelled. This cooling system radiator instead; vehicles turbocharging system (turbo-compressor) produced by compressed air or atmospheric air intake of the engine intake air in the vehicle and conservator similar container means is passed through the hot water, hot engine coolant cooling as a result of evaporation in the air, the engine cooling system to realize, of pressure with steam and pressurized engine intake air, the capacity of the enlarged vehicle inter-the water vapour passing through the cooler to be condensed by heat transfer method and intercooler outlet in the air vortex motion is built and low pressure loss, central air operated liquid separator system with several methods in cold sleep decomposed transferring the engine coolant system is discussed topic.
\end{abstract}

The prototype vehicle has been prepared for developed engine cooling system. Validation studies were performed with the tests performed on the prototype vehicle. Cost analysis of the system is also carried out.

\section{INTRODUCTION}

Within the automotive industry, the area of vehicle design is moving rapidly into the use of new, high technology techniques. The purpose of a motor vehicle cooling system is to ensure that the engine is maintained at its most efficient practical operating temperature. The current trend in car engine design is towards smaller more efficient engines, but this result is less waste energy being available for heating purposes and passenger comfort. Current high efficiency engine systems create hot engine compartments, hot exhausts, hot lubricating oil, but poor heat output to the passenger compartment, at least from cold starting conditions. There is a need to look at the total heat balance and control system for the vehicle in order to search for performance optimization and cost saving [1].

Although petroleum engines have improved a lot, they are still not very efficient at turning chemical energy into mechanical power. Most of the energy in the gasoline (perhaps 70\%) is converted into heat, and it is the job of the cooling system to take care of that heat. In fact, the cooling system on a car driving down the freeway dissipates enough heat to heat two averagesized houses! The primary job of the cooling system is to keep the engine from overheating 
by transferring this heat to the air, but the cooling system also has several other important jobs. The engine in your car runs best at a fairly high temperature. When the engine is cold, components wear out faster, and the engine is less efficient and emits more pollution. So another important job of the cooling system is to allow the engine to heat up as quickly as possible, and then to keep the engine at a constant temperature [2].

Combustion of air and fuel takes place inside the engine cylinder and hot gases are generated inside an internal combustion engine. The temperature of gases may raise up to around 2300$2500{ }^{\circ} \mathrm{C}$, which is a very high temperature and may result into burning of oil film between the moving parts, pre combustion and may result into seizing or welding of the moving parts. So, this temperature must be reduced to lower values at which the engine will work properly and much more efficiently [3]. A lot of the heat from this combustion goes right out the exhaust system, but some of it soaks into the engine, heating it up (Figure 1). The engine runs best when its coolant is about 200 degrees Fahrenheit (93 degrees Celsius). At this temperature [2]:

- The combustion chamber is hot enough to completely vaporize the fuel, providing better combustion and reducing emissions.

- The oil used to lubricate the engine has a lower viscosity (it is thinner), so the engine parts move more freely and the engine wastes less power moving its own components around.

- Metal parts wear less.

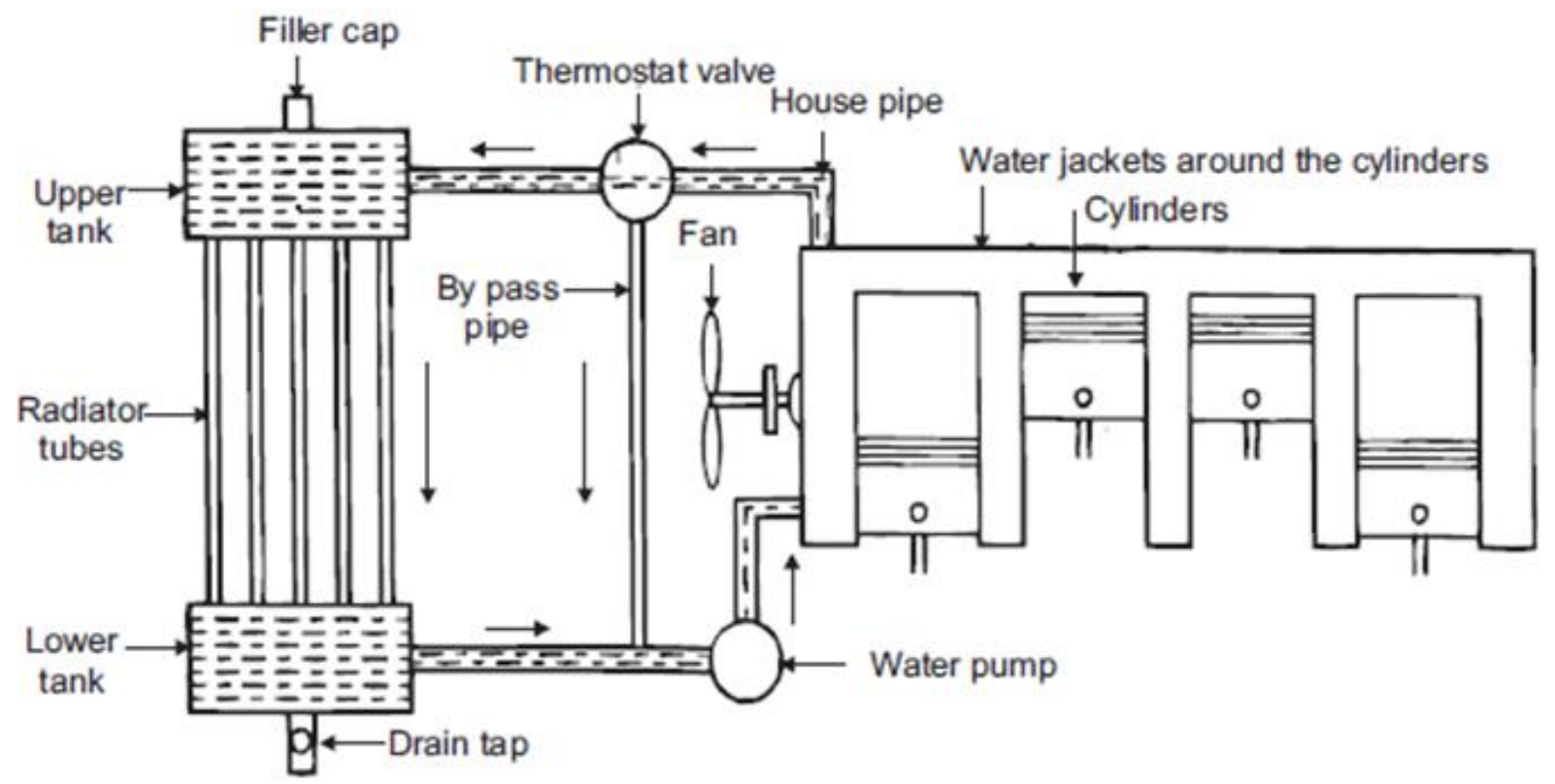

Figure 1. Water cooling system of a 4-cylinder engine [4]

Actually, there are two types of cooling systems found on motor vehicles: Liquid cooled and Air cooled. Air cooled engines are found on a few older cars, like the original Volkswagen Beetle, the Chevrolet Corvair and a few others. Many modern motorcycles still use air cooling, but for the most part, automobiles and trucks use liquid cooled systems and that is what this article will concentrate on [5]. 
A radiator is a type of heat exchanger. It is designed to transfer heat from the hot coolant that flows through it to the air blown through it by the fan. Most modern cars use aluminium radiators. These radiators are made by brazing thin aluminium fins to flattened aluminium tubes. The coolant flows from the inlet to the outlet through many tubes mounted in a parallel arrangement. The fins conduct the heat from the tubes and transfer it to the air flowing through the radiator. The tubes sometimes have a type of fin inserted into them called a tabulator, which increases the turbulence of the fluid flowing through the tubes. If the fluid flowed very smoothly through the tubes, only the fluid actually touching the tubes would be cooled directly. The amount of heat transferred to the tubes from the fluid running through them depends on the difference in temperature between the tube and the fluid touching it. So if the fluid that is in contact with the tube cools down quickly, less heat will be transferred. By creating turbulence inside the tube, all of the fluid mixes together, keeping the temperature of the fluid touching the tubes up so that more heat can be extracted, and all of the fluid inside the tube is used effectively. Radiators usually have a tank on each side, and inside the tank is a transmission cooler [3].

\section{GENERAL INFORMATION}

Today in general, cooling fluid that used in the engine cooling system in vehicles, compositions of ethylene glycol [6] and $\mathrm{H} 2 \mathrm{O}$ (water) occurs. Hot water that taken from the motor $(\mathrm{M})$ by circulation pump $(\mathrm{P})$ passed through the radiator pipe (Figure 2). When the engine coolant temperature rises above the specified value, air passed through the radiator by the electric engine and fan assembly. So that, the water temperature reduced and it is sent to the engine again from the water return line. Expansion tank to prevent damage to the equipment $(\mathrm{G})$ is used, as a result of the expansion of water with heating of the engine cooling fluid and the thermal a widening. The expansion tank placed highest point of circulates engine coolant line in vehicle. Because, if there is air in the system, due to the difference intensity, air rises above expansion tank $(\mathrm{G})$ that highest point of the cooling system. Because there is a cap with the selectively permeable structure on the expansion tank, air is discharged here. Engine cooling systems operate in closed circuit and working pressure up to 1.5 times sealevel open-air pressure. Turbo compressor increases the pressure of the engine intake air. Increasing air pressure heats up. The intercooler cools the heated air and air is sent to engine. Average air flow of $0.1 \mathrm{~kg} / \mathrm{s}$ for $1600 \mathrm{cc}$ engine's.

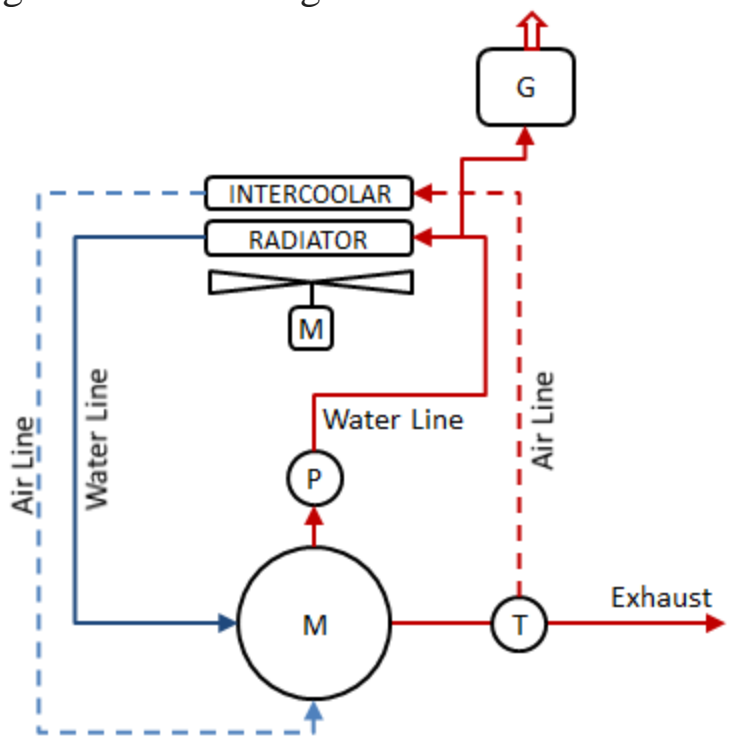

Figure 2. Current engine cooling and air intake system 
Before starting to work for the car to do the prototype engine coolant temperature were measured (Figure 3). After the study, it will be possible to compare measurements when repeated.

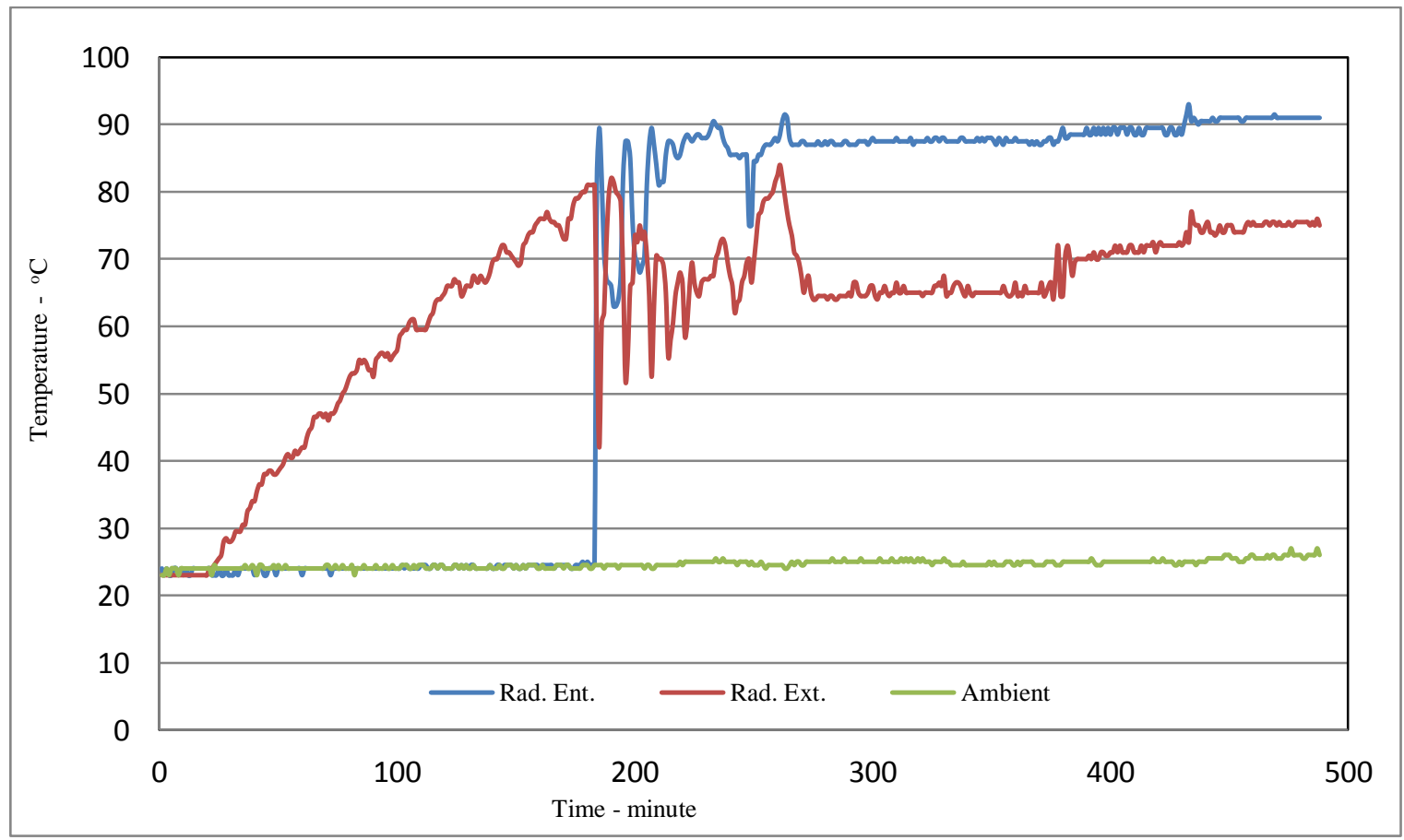

Figure 3: 98/69/EC test results for a current vehicle's engine cooling system on cities internal and external performance cycle

In this study, radiator and fan electric motor has been canceled for cars with turbo and intercooler system in developed cooling system (Figure 4). Instead of canceled parts, a second expansion tank (G2) and an air flow amplifier with pressure ratio 18-20 are used. Components interconnections are altered by changing the working principle of the cooling system. Corrosion inhibitors [7] and 50\% by weight $\mathrm{LiBr}$ [8] were added in vehicle cooling water

Hot coolant from the engine comes first the G1 expansion tank. Engine output water temperature is over $90{ }^{\circ} \mathrm{C}$, water evaporates from the solution of $\mathrm{LiBr}$ in the air mixed with hot water and hot engine cooling water cools down with the heat of vaporization. The air that water vapour contained in is cooled in the vehicle's intercooler. Also as a result of the water vapour is condensed and water is given to the G1 expansion tank. 


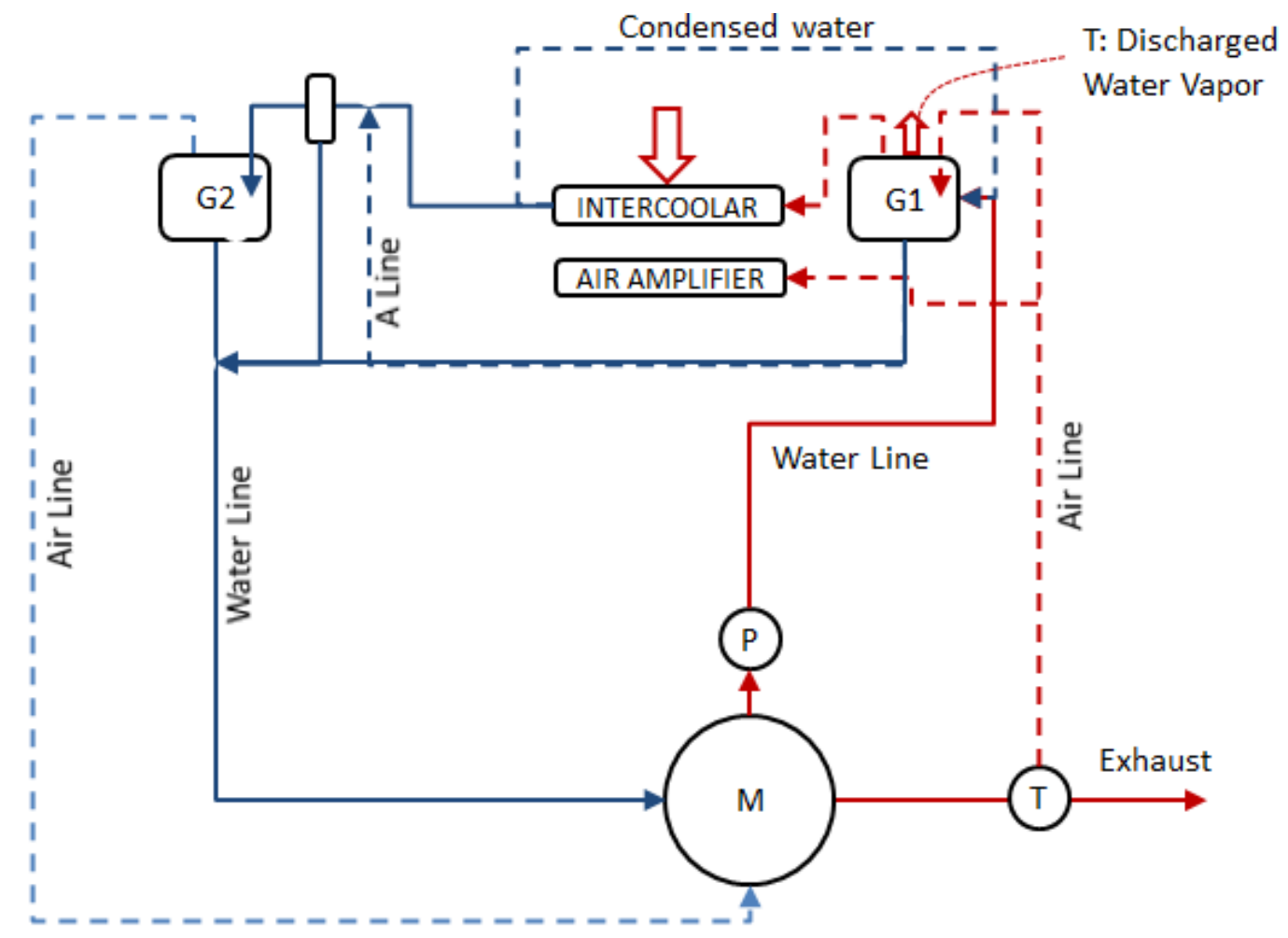

Figure 4. Suggested cooling cycle scheme

The $\mathrm{LiBr}$ solution to absorb water vapor characterized in slightly above the atmospheric temperature, relative humidity of the air emerging from the second expansion tank is lower than entered ambient air at the same temperature relative. In other words, because water condenses in the air, it increases the amount of engine cooling water. A portion of the water evaporated from the air humidified in the $\mathrm{LiBr}$ solution is discharged before the inlet intercooler. Thus $\mathrm{LiBr}$ solution is renewed and would not lose the absorbed water feature. Increased water content because water evaporates from the air inside the engine coolant and more water evaporates due to the water vapor from the solution loses its ability to absorb with a reduction ratio of $\mathrm{LiBr}$ solution. When the water content is reduced, evaporation temperature increases, not evaporate and the mixture richer, it increases the amount of condensation water from air. In this way, the engine cooling water temperature and the solution continually keeps constant its concentration. Also it does not require a control system. Air amplifier fed with a quantity of compressed air from the turbo compressor, compressed feed air compressing about 15 times and sends over intercooler (Figure 5). Air flow is achieved without electric motor, fan moving and electrical installation parts

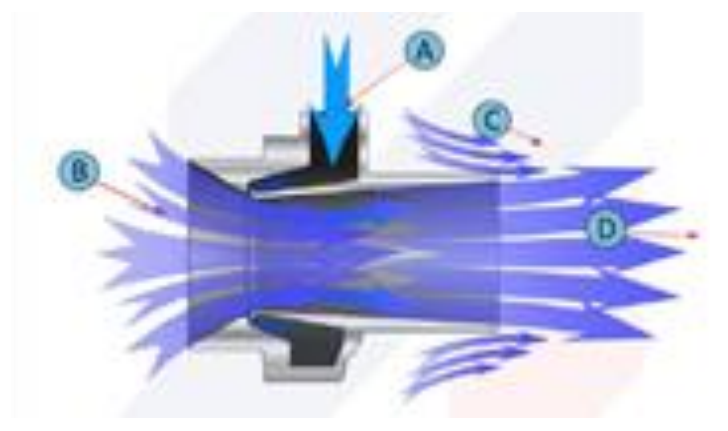

Figure 5. Air flow amplifier [9] 
When the air blow with air flow amplifier to intercooler, air-water vapour mixture is cooled fast and efficient in intercooler. Intercooler size both the air cooling and condensation of water vapor in air is enlarged. In the present application, the air in intercooler and water in the radiator cooled. In this study, a water vapor saturated air cooled in intercooler and due to the decomposition condenses in the air through cooling water, heat transfer coefficient (changing phase in the cooling system) increases. These reasons, heat transfer surface is required less than the current systems.

Axial fans used to cool the air in the radiator prepared for the proposed prototype system has been canceled. Instead of canceled fan, engine cooling fan working air amplifier (400 1/min flow with 0.4 bar) on vehicles with air pressure turbo is used [9]. Then, prepared new cooling system without radiator on the vehicle (Figure 4). LiBr not added to engine coolant. In this case, caused by evaporation during the test aimed to measure the amount of water loss.
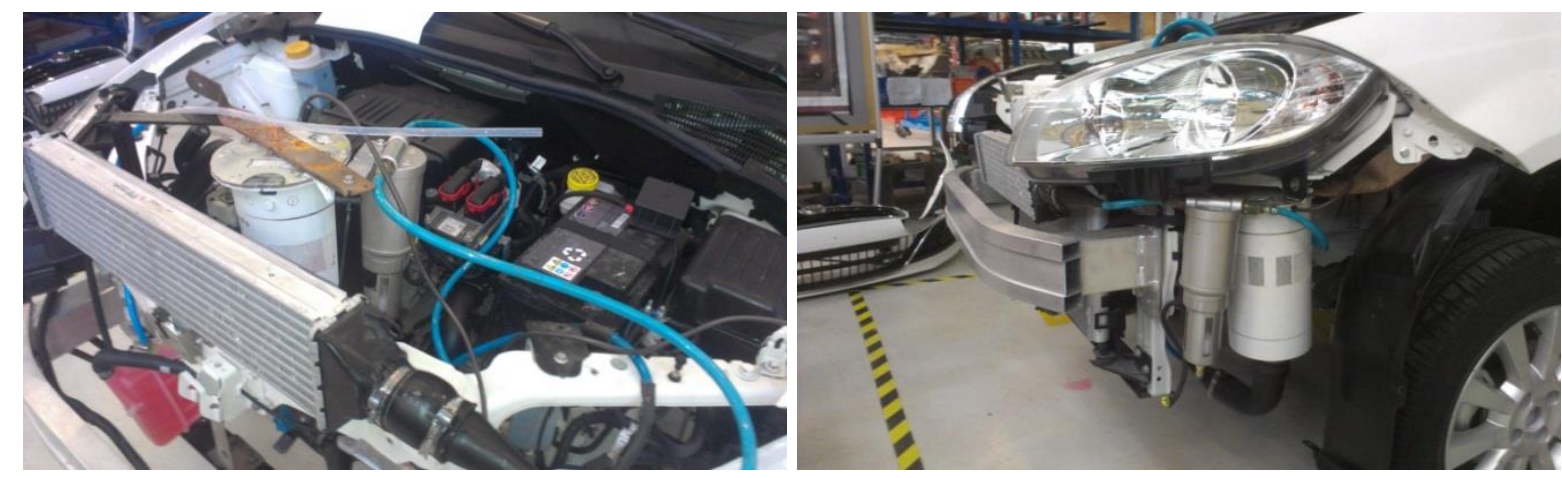

Figure 4. Prototype vehicle without axial fan and radiator

The prototype vehicle engine coolant temperatures were measured. Measured values are shown in Figure 5. Applying the urban and out of urban cycle used in European emission measurement temperature change were measured [10]. Engine coolant is higher than the current car. Engine coolant temperature can operate at $120{ }^{\circ} \mathrm{C}$, but the current system is $90{ }^{\circ} \mathrm{C}$ set to stay far from the evaporation temperature of water. Evaporation of the water in the newly developed system, does not constitute a problem because the part of the operation of the system. Therefore, the engine coolant temperature is $120^{\circ} \mathrm{C}$ remained below the desired level.

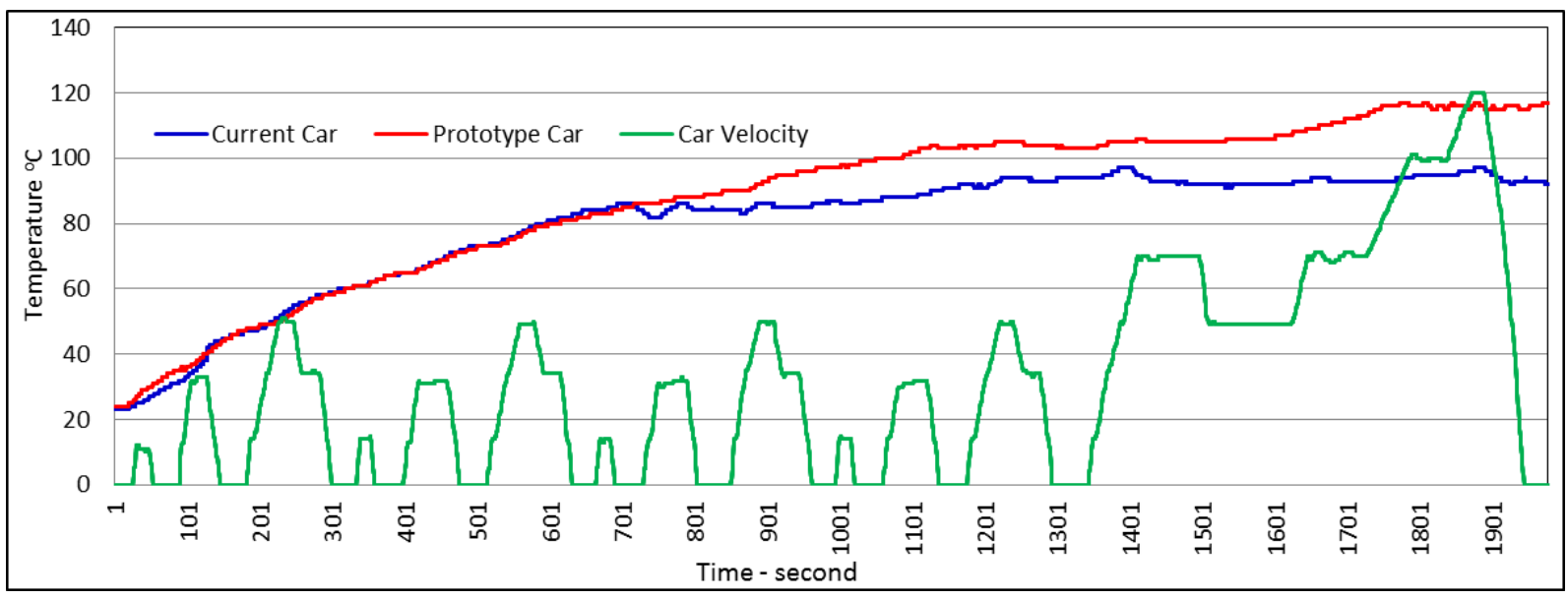

Figure 5. Engine coolant temperature change for operating cycle for the Type I 
The prototype vehicle that before and after the changes are applied was subjected to noise and vibration testing. First vehicle exterior noise level measurements have been made for this. This value is measured at a distance from the vehicle to $1 \mathrm{~m}$.
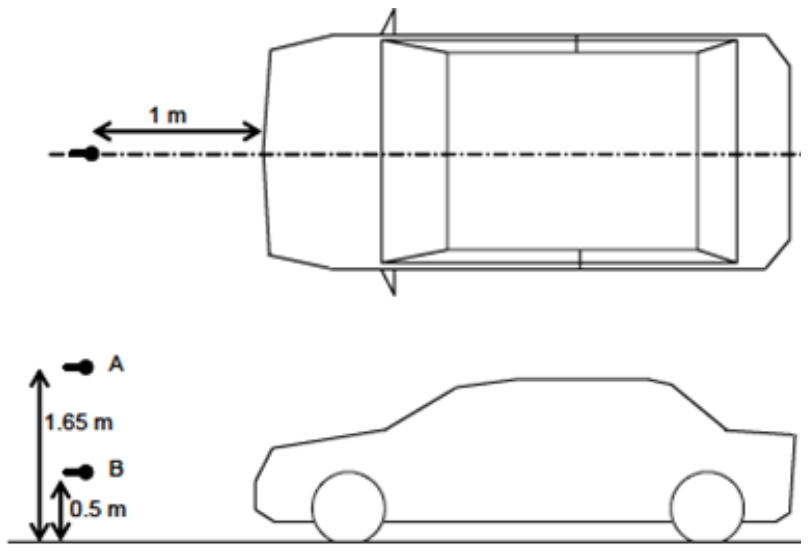

Figure 6. Vehicle exterior noise level measurement positions

Vehicle exterior noise measurements carried out on non-significant difference was observed (Figure 7). A negative impact on the external noise level of the cooling system is not recommended.
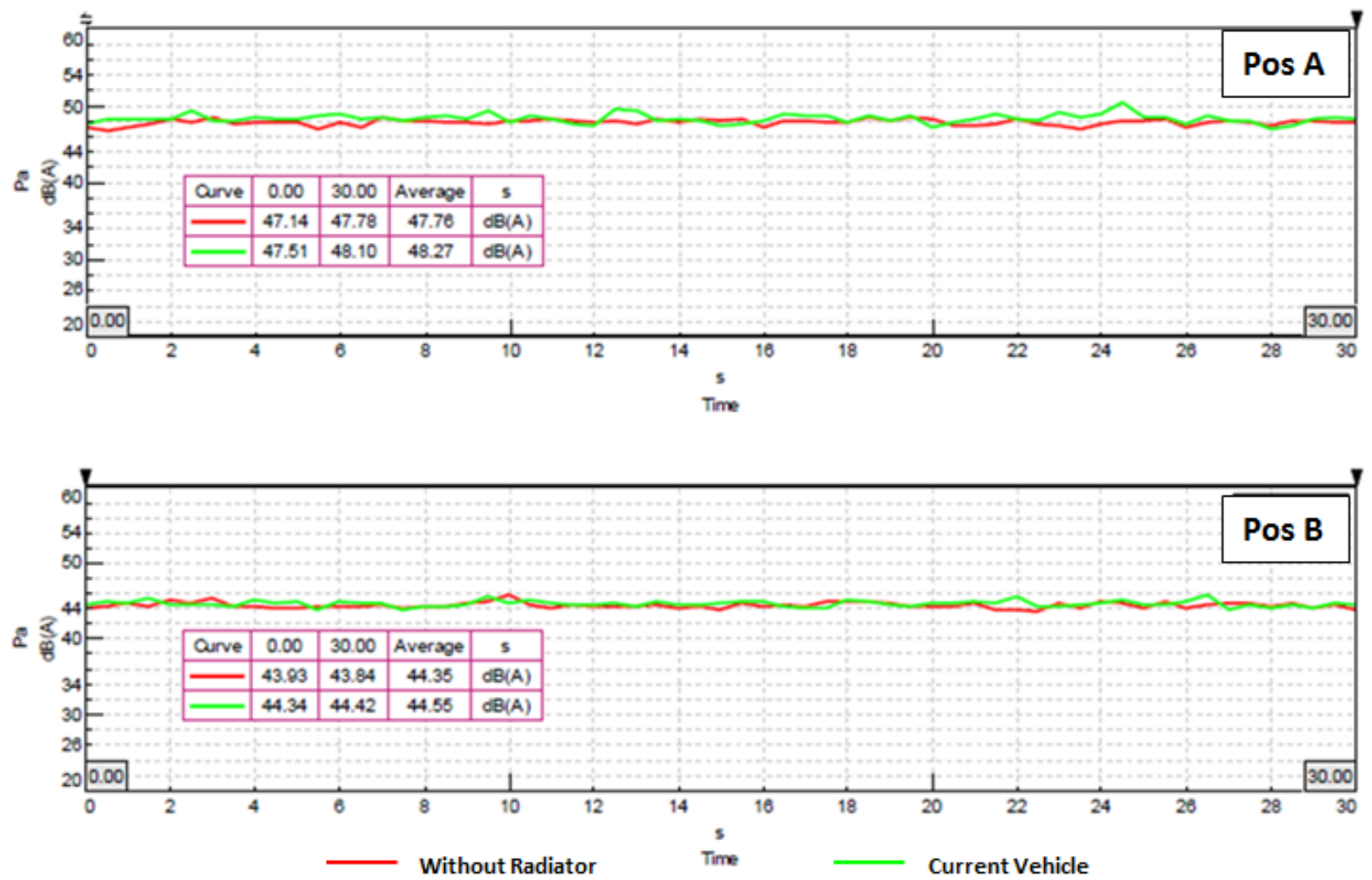

Figure 7. Vehicle exterior noise level measurement results

In the developed system, steering vibration was measured, due to the newly added parts and canceling the radiator cooling fan motor (Figure 8). According to test results over the steering wheel oscillation index value of $1 \mathrm{~m} / \mathrm{s}^{2}$ has been shown to be higher. These values are acceptable levels for vehicle production. 

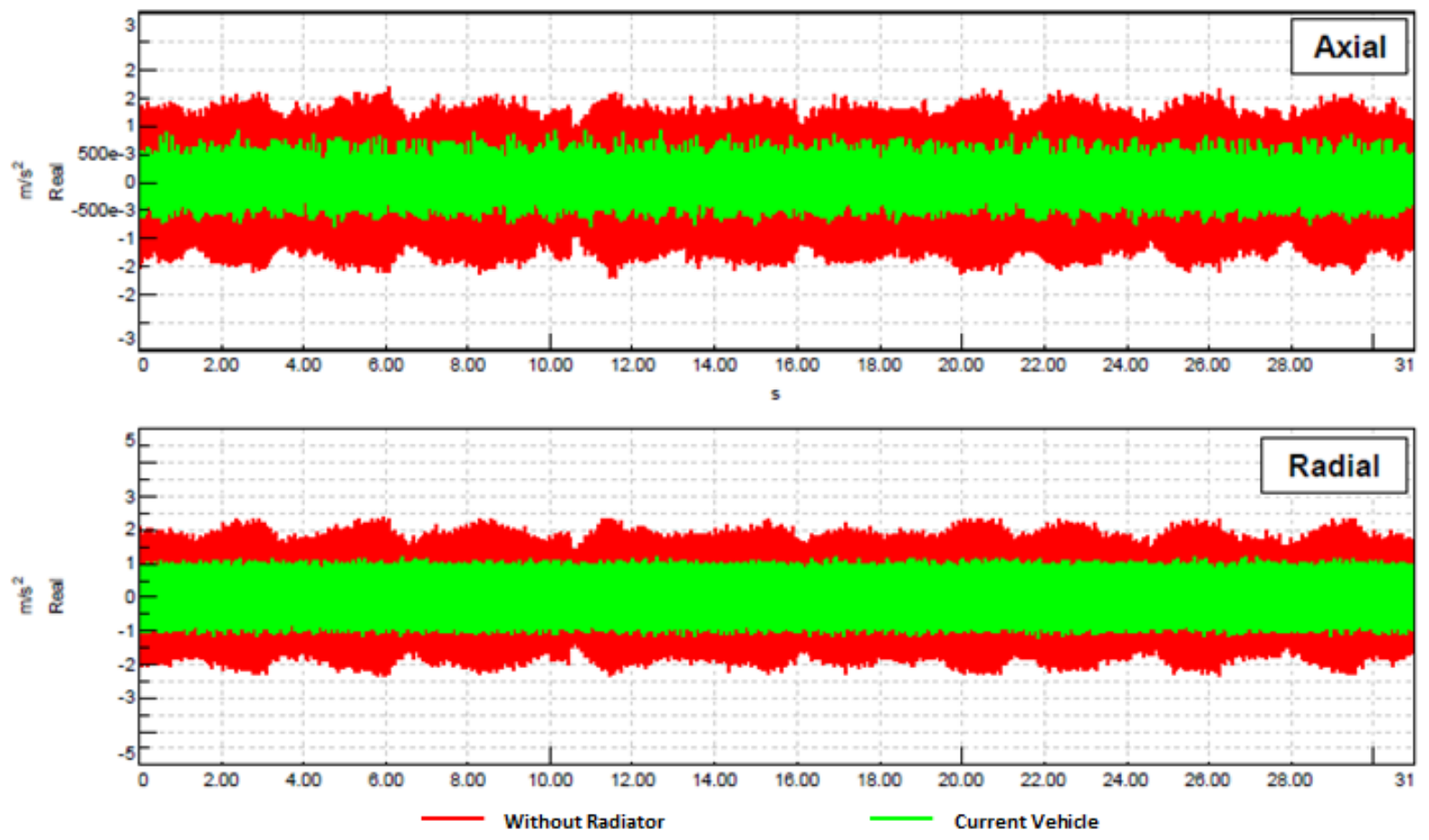

Figure 8. Steering wheel vibration test measurement results

\section{CONCLUSION}

The radiators fitted in current engine cooling system are limited by air side resistance and require a large frontal area to meet cooling needs and at high speeds it is difficult to maintain the temperature of engine components. But this system is independent of vehicle speed developed.

The engine coolant temperature of about $90{ }^{\circ} \mathrm{C}$ in the vehicle with radiators was found to be $120{ }^{\circ} \mathrm{C}$ is canceled radiator. The cause of this difference between the calculated and physical measurement, it is known to result from the different fluid and air flow Solutions must be found to provide increased airflow for to reduce this temperature

Prototype vehicle tested in the electric air pump instead of the turbo compressor (electric compressor) is used. Thus, it was found value independently of engine speed in constant air flow. After this study, cooling efficiency must be controlled using air from the vehicle turbo compressor

When unused $\mathrm{LiBr}$ in tanks, reduction would seem to be in the engine cooling water. Therefore $\mathrm{LiBr}$ material should be used in tanks and thus water comes out due to the condensation ambient air. Humid air is thrown out must have a drainage system to drain this water

Canceling the radiator in the car and instead use an additional tank with a total weight of 1.4 $\mathrm{kg}$ and has obtained a cost saving about $13 €$

3 patents were taken for innovations in studies [11, 12 and 13] 
Study was performed by variations on an existing vehicle. Controls the conditions of forced engine coolant temperature, temperature changes of engine space, road and tests should be done. Also part of the design should be completed according to the results to be obtained from the test.

\section{REFERENCES}

[1] PARK, Kyoung Suk; WON, Jong Phil; HEO, Hyung Seok. Thermal Flow Analysis of Vehicle Engine Cooling System. KSME International Journal, Vol. 16, No. 7, pp 975985, 2002

[2] AURT202170A Inspect \& Service Cooling System. Automotive Industry Training Retail, Service and Repair Auro. Automotive Training Board, 2008

[3] SAINI, Abhishek; BISHT, Krishna Singh; MISHRA, Sudhanshu. Advance Engine Cooling System, International Journal of Advanced Technology \& Engineering Research (IJATER), 2014

[4] http://www.ignou.ac.in/upload/unit\%205.pdf Accessed on: May 2015

[5] PRUDHVI, Gogineni; VINAY, Vinay; BABU, G.Suresh. Cooling Systems in Automobiles \& Cars. International Journal of Engineering and Advanced Technology (IJEAT). ISSN: 2249-8958, Volume-2, Issue-4, April 2013

[6] http://www.meglobal.biz/monoethylene-glycol/physical-properties Accessed on: May 2015

[7] http://www.fmclithium.com/Portals/FMCLithium/content/docs/DataSheet/QS-PDS1003\%20r0.pdf Accessed on: May 2015

[8] http://www.fmclithium.com/Portals/FMCLithium/content/docs/DataSheet/QS-PDS1001\%20r0.pdf Accessed on: May 2015

[9] http://www.erkim.com.tr/pdfler/Section D Air Amplifier.pdf Accessed on: May 2015

[10] EEC-70220. To Measures To Be Taken Against Air Pollution By Emissions From Motor Vehicles. April 6, 1970

[11] AYARTURK, Hasan; ODABASIOGLU, Arda; DURGUN, İsmail. Axial Fan Unused Engine Cooling System. Engineering and Technology Symposium, Çankaya University, 14-15 May 2015

[12] AYARTÜRK, Hasan; ODABAŞIOĞLU, Arda. Cooling System Without Serpentine For Vehicles. TR 2014/14489, 2014

[13] AYARTÜRK, Hasan; ODABAŞIOĞLU, Arda. Common Heat Exchanger Vehicle. Patent, TR 2014/04550, 2014

[14] AYARTÜRK, Hasan; ODABAŞIOĞLU, Arda; DEDEOĞLU, Şeref. A Cooling System. Patent, TR2013/15038, 2013 